\title{
Partial Least Squares and Continuous Wavelet Transformation in Simultaneous Spectrophotometric Determination of Amlodipin and Atorvastatine
}

\author{
Masoud Shariati-Rad ${ }^{1 *}$, Mohsen Irandoust ${ }^{1}$, Tayyebeh Amini ${ }^{1}$ and Farhad Ahmadi ${ }^{2}$ \\ ${ }^{1}$ Department of Analytical Chemistry, Faculty of Chemistry, Razi University, Kermanshah, Iran \\ ${ }^{2}$ Department of Medicinal Chemistry, Faculty of Pharmacy, Kermanshah University of Medical Sciences, Kermanshah, Iran
}

\begin{abstract}
A simple spectrophotometric method for simultaneous determination of amlodipin and atorvastatine in pharmaceutical preparation is proposed based on the partial least squares and continuous wavelet transformation. The resulted partial least squares models were employed for prediction of the two drugs in two brands of combined pharmaceutical preparations which resulted in percent recoveries of 100.7 and 101.4 for amlodipin and 98.6 and 100.1 for atorvastatine. In the best conditions, the results of percent recoveries by continuous wavelet transformation zero-crossing were: 110.3 and 109.0 for amlodipin and 99.7 and 99.7 for atorvastatine for brand 1 and 2 , respectively.
\end{abstract}

Keywords: Partial least squares; Continuous wavelet transformation; Recovery; Atorvastatine; Amlodipin

\section{Introduction}

Amlodipin (AM), 2[(2-aminoethoxy) methyl]-4-(2-chlorophenyl)-1, 4-dihydro-6-methyl-3, 5-pyridine carboxylic acid, 3-ethyl, 5-methylester (Figure 1) [1] is a dihydropyridine derivative with calcium antagonist activity. It is used in the management of hypertension, chronic stable angina pectoris and prinzmetal variant angina [2]. AM inhibits the transmembrane influx of calcium ions into vascular smooth muscle and cardiac muscle [3]. Atorvastatine (AT) is chemically described as $\left[R-\left(R^{*}, R^{*}\right)\right]-2$-(4-fluorophenyl), $\beta, \delta$-dihydroxy5-(1-methylethyl)-3-phenyl-4-[(phenylamino) carbonyl]-1H-pyrrole1-heptanoic acid (Figure 1) [1]. AT is a selective, competitive inhibitor of HMG-CoA reductase, the rate-limiting enzyme that converts 3-hydroxy-3-methylglutaryl-coenzyme A to mevalonate, a precursor of the sterols, including cholesterol. It is used to reduce LDL-cholesterol, apolipoprotein B, and triglycerides and to increase HDL-cholesterol in the treatment of hyper-lipidaemias [3].

There are several combined commercial product of these two drugs [4]. Many methods have been reported for the determination of either AM [5-11] or AT [12-17] alone or in combination with other drugs in pharmaceutical dosage forms or individually in biological fluids.

Only two papers have reported simultaneous determination of $\mathrm{AM}$ and AT which are based on HPLC $[4,18]$. However, none of the reported analytical methods describe simultaneous determination of

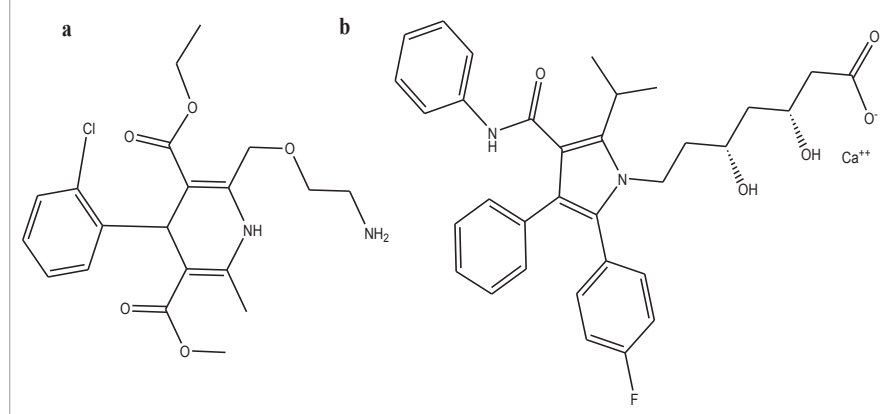

Figure 1: Structural formula of (a) amlodipin and (b) atorvastatine.
AM and AT using spectrophotometrics methods. To our knowledge, this is the first report for the simultaneous determination of both $\mathrm{AM}$ and $\mathrm{AT}$ in pharmaceutical preparations. The present manuscript describes a simple, rapid, precise and accurate spectrophotometric method using partial least squares (PLS) as a multivariate calibration method for the simultaneous determination of AT and AM in the pharmaceutical preparations.

PLS is a useful chemometrics tool for analysis of complex mixtures, because it enables rapid and simultaneous determination of each component in the mixture, with minimum sample preparation and without the need for lengthy separations $[19,20]$.

Continuous wavelet transformation (CWT) with zero-crossing has been applied for multi-component determination [21-23]. The importance of CWT comes from the transformation of the original signal to the other forms.

\section{Theory \\ Partial least squares (PLS)}

PLS is a predictive two-block regression method based on estimated latent variables (LVs) and is applied to the simultaneous analysis of two datasets (e.g. spectra and concentration) on the same objects $[19,24]$.

The purpose of the PLS is to build a linear model enabling the prediction of desired characteristics e.g. concentration (involved in $\mathbf{y}$ ) from measured spectra (involved in $\mathrm{X}$ ). There is a linear model $\mathrm{y}=\mathrm{Xb}$ in matrix notation where $\mathbf{b}$ contains the regression coefficients that are

*Corresponding author: M. Shariati-Rad, Department of Analytical Chemistry, Faculty of Chemistry, Razi University, Kermanshah, Iran, Tel: +98 831 4274559; Fax: +98 831 4274559; E-mail: mshariati_rad@yahoo.com

Received October 15, 2012; Accepted October 27, 2012; Published October 30 2012

Citation: Shariati-Rad M, Irandoust M, Amini T, Ahmadi F (2012) Partial Least Squares and Continuous Wavelet Transformation in Simultaneous Spectrophotometric Determination of Amlodipin and Atorvastatine. Pharmaceut Anal Acta 3:178. doi:10.4172/2153-2435.1000178

Copyright: (c) 2012 Shariati-Rad M, et al. This is an open-access article distributed under the terms of the Creative Commons Attribution License, which permits unrestricted use, distribution, and reproduction in any medium, provided the original author and source are credited. 
Citation: Shariati-Rad M, Irandoust M, Amini T, Ahmadi F (2012) Partial Least Squares and Continuous Wavelet Transformation in Simultaneous Spectrophotometric Determination of Amlodipin and Atorvastatine. Pharmaceut Anal Acta 3:178. doi:10.4172/2153-2435.1000178

Page 2 of 7

determined during the calibration step, and $\mathrm{X}$ is the matrix of collected spectra. PLS was firstly applied to evaluate near infrared (NIR) spectra by Martens and Jensen [24] and is now used routinely in academic institutions and industry to correlate instrumental measurements with related chemical/physical data.

Interestingly, multivariate method PLS1 is advantageous and appealing for the determination of analytes in complex matrices, because calibration does not require knowledge of the concentrations of all other components except the analyte of interest. However, interferences should be present in the calibration set in order to be modeled and taken into account during the prediction step.

\section{Continuous wavelet transformation (CWT)}

A wavelet is a waveform of effectively limited duration that has an average value of zero. Wavelet analysis is the breaking up of a signal into shifted and scaled versions of the original (or mother) wavelet $[25,26]$.

The continuous wavelet transform (CWT) is defined as the sum over all wavelength $(\lambda)$ of the signal $(f(\lambda))$ multiplied by scaled, shifted versions of the mother wavelet function $\Psi$ :

$$
\begin{aligned}
& C(\text { scale, position })=\int_{-\infty}^{+\infty} f(\lambda) \psi(\text { scale, position }, \lambda) d \lambda=\frac{1}{\sqrt{s}} \int_{-\infty}^{+\infty} f(\lambda) \\
& \psi\left(\frac{\lambda-\tau}{s}\right) d \lambda
\end{aligned}
$$

The result of the CWT is many wavelet coefficients $C$, which are a function of scale $(s)$ and position $(\tau)$. Multiplying each coefficient by the appropriately scaled and shifted wavelet yields the constituent wavelets of the original signal. We have already seen that wavelet analysis produces a wavelength-scale view of the signal. Now, we introduce scaling and shifting wavelets. Scaling a wavelet simply means stretching (or compressing) it. This is shown by scale factors. The scale factor works exactly the same with wavelets. Shifting is shown by $\tau$.

The wavelet is placed at the beginning of the signal at the point which corresponds to the first wavelength. The wavelet function at scale " 1 " is multiplied by the signal and then integrated over all wavelengths. The final result is the value of the transformation, i.e., the value of the continuous wavelet transform at first wavelength and scale $s=1$. In other words, it is the value that corresponds to the point $\tau=0, s=1$ in the wavelength-scale plane. The wavelet at scale $s=1$ is then shifted towards the right by $\tau$ amount to the location $\lambda=\tau$, and the above equation is computed to get the transform value at $\lambda=\tau, s=1$. This procedure is repeated until the wavelet reaches the end of the signal. One row of points on the wavelength-scale plane for the scale $s=1$ is now completed. Then, $s$ is increased by a small value. Note that, this is a continuous transform, and therefore, both $\tau$ and $s$ must be incremented continuously. When the process is completed for all desired values of $s$, the CWT of the signal has been calculated.

At every location, it is multiplied by the signal. Obviously, the product is nonzero only where the signal falls in the region of support of the wavelet, and it is zero elsewhere (zero-crosses points). If the signal has a spectral component that corresponds to the current value of $s$ (which is 1 in this case), the product of the wavelet with the signal at the location where this spectral component exists gives a relatively large value. If the spectral component that corresponds to the current value of $s$ is not present in the signal, the product value will be relatively small, or zero.

For quantitation by CWT in binary mixtures, calibration of each analyte in the mixture can be performed by modelling CWT-signal against concentration at zero-crosses of the second component.

In this study, Mexican hat (Mexh) and Morlet were used as mother wavelets which the former gave better results.

In this study, Mexican hat (Mexh) and Morlet were used as mother wavelets which the former gave better results.

\section{Statistical measures and figures of merits of the PLS model}

Quantitatively, all model performances of PLS are expressed in terms of root mean square error of cross-validation (RMSECV), root mean square error of prediction (RMSEP), and cross-validated correlation coefficient $\left(Q^{2}\right)[27]$ :

RMSECV $=\sqrt{\frac{\sum_{i=1}^{m}\left(c_{i}-\hat{c}_{i}\right)^{2}}{m}}$

$R M S E P=\sqrt{\frac{\sum_{i=1}^{n}\left(c_{i}-\hat{c}_{i}\right)^{2}}{n}}$

$$
Q^{2}=1-\frac{\sum_{i=1}^{n}\left(c_{i}-\hat{c}_{i}\right)^{2}}{\sum_{i=1}^{n}\left(c_{i}-c_{\text {mean }}\right)^{2}}
$$

In all of these expressions, $c_{i}, \hat{c}_{i}$, and $c_{\text {mean }}$ are the real and predicted concentration of the component, and mean of the real concentrations, respectively. It must be mentioned that $c_{i}$ and $\hat{c}_{i}$ in Eq. (2) are those in calibration set and $c_{i}, \hat{c}_{i}$, and $c_{\text {mean }}$ in Eqs. (3) and (4) are those in validation set. $m$ and $n$ are the number of the samples in the calibration and validation sets, respectively. RMSECV was calculated in a leave-one-out approach. The F statistic was used to make the significance determination of the number of LVs and to avoid over-fitting [28].

Selectivity, sensitivity, and limit of determination can be calculated and used for method comparison or to study the quality of a given analytical technique.

One method for calculation of the figures of merits of the multivariate calibration methods relies on net analyte signal (NAS) calculations. The method was extended to inverse multivariate methods like PLS by Lorber [29]. In this definition, LOD is defined as

$$
L O D=\Delta(\alpha, \beta) \delta r
$$

where $\Delta(\alpha, \beta)$ is the noncentrality parameter of a non-central t-distribution, which can be calculated numerically or taken from statistical tables [30] and $\delta r$ is an estimate for the standard deviation of the measurement errors.

NAS calculations also allow estimation of other figures of merit such as the selectivity for $k^{\text {th }}$ component [31]:

$$
S E L=\frac{\left\|s_{k}^{*}\right\|}{\left\|s_{k}\right\|}
$$

and its sensitivity 


$$
\text { SEN }=\frac{1}{\|b\|}
$$

where $\mathrm{b}$ is the vector of final regression coefficients, which can be obtained by any multivariate method. $s_{k}$ is the pure spectrum of the analyte ( $k$ th component) in unite concentration and $s_{k}^{*}$ is the NAS of the analyte.

Another useful parameter is analytical sensitivity $\gamma$. It may be defined, in analogy to univariate calibration, as the quotient:

$$
\gamma=\frac{S E N}{\delta r}
$$

\section{Experimental}

\section{Apparatus and software}

An Agilent 8453 UV-Vis spectrophotometer with diode array detector connected to a computer equipped with ChemStation software was used for recording of the absorption spectra of the compounds and their samples in the spectral range of 200-320 nm. The treatment of the absorption spectral data was performed by using MATLAB 6.5 software (MATLAB 6.5, The Mathworks Inc., Natick). PLS multivariate calibrations were performed using a series of $\mathrm{m}$-files written in MATLAB environment.

\section{Standard solutions}

All solutions were prepared with analytical-reagent grade chemicals. Stock solutions of the pure compounds (AM and AT) were separately prepared by dissolving $20 \mathrm{mg}$ of AM and AT in $100 \mathrm{ml}$ mixture of methanol-water $(20: 80, \mathrm{v} / \mathrm{v})$ in a calibrated flask. Standard calibration solutions in the studied concentration ranges were obtained by appropriate dilution of the above standard solutions.

\section{Analysis of tablet formulations}

Ten tablets of AM-AT co-formulation (two different brands) were accurately weighed and grounded to fine powder and a sample of the powder equivalent to the amount of a tablet was accurately weighed and transferred into a $100 \mathrm{~mL}$ volumetric flask. $20 \mathrm{~mL}$ of methanol was added and the mixture was stirred for $30 \mathrm{~min}$ at room temperature. Then, it was diluted to volume with doubly distilled water and mixed. This solution was filtered through a Whatman paper. A $10 \mathrm{~mL}$ aliquot of filtrate was transformed in a $100 \mathrm{~mL}$ volumetric flask and completed to the mark with methanol-water mixture $(20: 80, \mathrm{v} / \mathrm{v})$ and mixed. This sample was then submitted for the analysis.

\section{Results and Discussion}

Figure 2 displays the UV absorption spectra for AM and AT in the standard solutions recorded between 205 and $310 \mathrm{~nm}$. As can be seen they overlap severely. In order to find the linear dynamic range for each compound, possible concentration levels of the related compounds were tested (0.1-100.0 $\mathrm{mg} \mathrm{L}^{-1}$ for AM and $0.3-100.0 \mathrm{mg} \mathrm{L}^{-1}$ for AT). Individual calibration curves were constructed with more than 25 points as absorbance versus drugs concentrations in the dynamic linear ranges and were evaluated by linear regression [32]. Statistical characteristics of the regression equations of individual calibrations using absorption UV spectra are shown in table 1 .

Determination of amlodipin and atorvastatine in synthetic binary mixtures using PLS multivariate calibration

AM shows a maximum absorbance at $246 \mathrm{~nm}$ and that of AT has

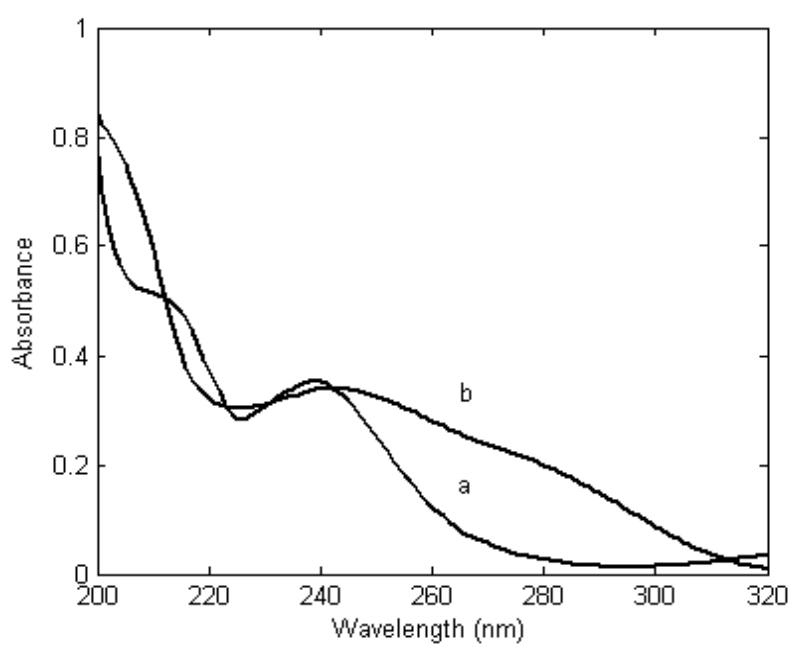

Figure 2: Absorption spectra of (a) $10 \mathrm{mg} \mathrm{L}^{-1}$ amlodipin and (b) $10 \mathrm{mg} \mathrm{L}^{-1}$ atorvastatine in methanol-water mixture $(20: 80, v / v)$.

\begin{tabular}{|l|c|c|}
\hline Parameter & AM & AT \\
\hline Sample number & 28 & 36 \\
\hline Linear range $\left(\mathrm{mgL}^{-1}\right)$ & $0.3-40.0$ & $0.1-100.0$ \\
\hline Intercept of calibration curve & $5.2 \times 10^{-3}$ & $2.3 \times 10^{-2}$ \\
\hline Slope of calibration curve & $3.7 \times 10^{-2}$ & $2.8 \times 10^{-2}$ \\
\hline Standard error of intercept & $2.1 \times 10^{-3}$ & $2.9 \times 10^{-3}$ \\
\hline Standard error of slope & $1.3 \times 10^{-4}$ & $8.5 \times 10^{-3}$ \\
\hline Correlation coefficient & 0.997 & 0.997 \\
\hline Limit of detection $\left(\mathrm{mgL}^{-1}\right)$ & $1.1 \times 10^{-2}$ & $6.2 \times 10^{-2}$ \\
\hline Limit of quantitation $\left(\mathrm{mgL}^{-1}\right)$ & $3.7 \times 10^{-2}$ & 0.2 \\
\hline
\end{tabular}

Table 1: Parameters resulted from univariate calibration for AM and AT.

been located at $240 \mathrm{~nm}$. For the both drugs, there exists an increasing trend of absorbance toward lower wavelengths (Figure 2). It is evident that spectra strongly overlap, making difficult the simultaneous determination of both drugs by classical methodology due to their severe mutual interference. Therefore, we expected that the use of multivariate calibration could be a better resource to circumvent spectral overlapping and mutual interference problems.

For simultaneous determination by PLS, 28 calibrations and 12 external test samples containing both AM and AT were prepared. Dividing the samples into calibration and validation sets was carried out by Kennard-Stone algorithm [33]. The concentration of AM and AT lye in their known linear absorbance-concentration ranges. In table 2 , the concentrations of standard calibration and external test samples have been represented. In order to evaluate the performance of the PLS models, 12 external test samples were considered in the validation set. The spectrum of each standard mixture was recorded in the wavelength range of 205 to $310 \mathrm{~nm}$ with $1 \mathrm{~nm}$ intervals. Therefore, the $\mathbf{X}$ matrix for calibration is of $28 \times 106$ and the matrix for external test set is of $12 \times 106$ dimensions.

Models were internally validated employing the well-known leave- 
Citation: Shariati-Rad M, Irandoust M, Amini T, Ahmadi F (2012) Partial Least Squares and Continuous Wavelet Transformation in Simultaneous Spectrophotometric Determination of Amlodipin and Atorvastatine. Pharmaceut Anal Acta 3:178. doi:10.4172/2153-2435.1000178

Page 4 of 7

one-out procedure, and the number of latent variables for prediction was chosen in agreement with the Haaland-Thomas criterion [28]. The statistical parameters and figure of merits found upon application of the PLS to calibration and external test sets have been given in table 3. High $Q^{2}$ and $R^{2}$ values and low RMSECV and RMSEP values indicate the validity of the multivariate calibration and the analytical method.

Determination of amlodipin and atorvastatine in synthetic binary mixtures using CWT zero-crossing

Two wavelet families of Mexican hat (Mexh) and Morlet (Morl) were tested to find the optimal signal processing function for obtaining reliable results in determination of the investigated analytes. Mexh was

\begin{tabular}{|c|c|c|}
\hline & $\mathrm{AM}\left(\mathrm{mgL}^{-1}\right)$ & $\operatorname{AT}\left(\mathrm{mgL}^{-1}\right)$ \\
\hline No. & \multicolumn{2}{|c|}{ Calibration set } \\
\hline 1 & 5.9 & 19.3 \\
\hline 2 & 3.3 & 10.8 \\
\hline 3 & 9.7 & 26.6 \\
\hline 4 & 9.8 & 12.7 \\
\hline 5 & 5.2 & 25.8 \\
\hline 6 & 8.3 & 16.5 \\
\hline 7 & 3.8 & 12.4 \\
\hline 8 & 6.9 & 21.8 \\
\hline 9 & 9.7 & 20.4 \\
\hline 10 & 3.5 & 17.6 \\
\hline 11 & 9.2 & 17.1 \\
\hline 12 & 2.4 & 21.2 \\
\hline 13 & 8.9 & 10.2 \\
\hline 14 & 7.7 & 26.3 \\
\hline 15 & 5.3 & 26.9 \\
\hline 16 & 4.6 & 10.7 \\
\hline 17 & 4.7 & 18.3 \\
\hline 18 & 9.4 & 19.3 \\
\hline 19 & 6.4 & 25.8 \\
\hline 20 & 4.1 & 22.8 \\
\hline 21 & 6.1 & 18.1 \\
\hline 22 & 6.3 & 20.8 \\
\hline 23 & 4.9 & 12.7 \\
\hline 24 & 7.8 & 28.6 \\
\hline 25 & 8.2 & 18.8 \\
\hline 26 & 5.9 & 11.1 \\
\hline 27 & 7.2 & 26.6 \\
\hline \multirow[t]{2}{*}{28} & 6.9 & 19.6 \\
\hline & \multicolumn{2}{|c|}{ External test set } \\
\hline 1 & 6.3 & 27.9 \\
\hline 2 & 8 & 10.9 \\
\hline 3 & 8.5 & 27.7 \\
\hline 4 & 5.8 & 27.8 \\
\hline 5 & 9.3 & 16.5 \\
\hline 6 & 5.3 & 11.6 \\
\hline 7 & 6 & 24.5 \\
\hline 8 & 7.5 & 20.8 \\
\hline 9 & 7.9 & 18.1 \\
\hline 10 & 9.1 & 17.5 \\
\hline 11 & 7.4 & 17.7 \\
\hline 12 & 6.9 & 24.5 \\
\hline
\end{tabular}

Table 2: Composition of the 40 binary mixtures of AM and AT used for PLS calibration and external test set.

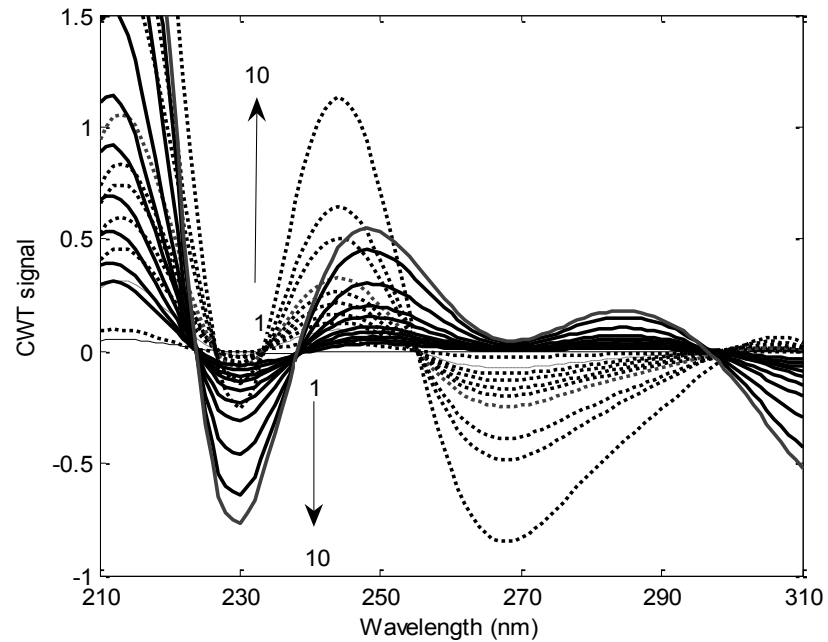

Figure 3: CWT signals of AM (dotted lines) and AT (solid lines) with concentrations of (1) 1.0, (2) 3.0, (3) 4.0, (4) 5.2, (5) 6.8, (6) 8.0, (7) 10.0, (8) 16.0, (9) 20.0 and (10) $35.0 \mathrm{mg} \mathrm{L}^{-1}$.

selected as optimal mother wavelet for transformation of absorption spectra.

The absorption spectra of the standard solutions of the AM and AT with different concentrations recorded in the wavelength range 205$310 \mathrm{~nm}$ were transferred to wavelet domain in MATLAB 7.1.

The optimum value of scaling factor for determination of AM and AT in their binary mixture was found as $a=10$. Figure 3 shows the graphs of CWT for calibration sets of AM and AT obtained by Mexh $(a=10)$ on the absorption spectra. Calibration graphs of AM were ob tained by measuring the CWT signals at 238, 268, 269, and $270 \mathrm{~nm}$ where the CWT signals of AT zero crosses at 235, 256, 309, and 310 $\mathrm{nm}$. Linear regression analyses and their statistical results have been reported in table 4. Application of these calibration models to synthetic binary mixtures in table 1 (the external test set) gave the results (Table $5)$.

\section{Assay of pharmaceutical formulations}

The methods developed were applied for the estimation of AM and AT in pharmaceutical preparations.

The calibration models were validated for accuracy and precision with five times determination of tablets contents. The precision is expressed as the RSD\%. The percentage recoveries and other statistics have been presented in tables 6 and 7 for PLS and CWT zero-crossing methods, respectively. As the data in table 6 show, the amounts of drugs were found to be within the range of $98.6-101.4 \%$ relative to the declared content by PLS method. None of the tablet excipients were found to interfere with the analyte determination. The analysis of tablets in most cases yielded RSD\% values below 2. The results, contained in table 6 , show that the proposed method is accurate and precise for both analytes.

\section{Comparison between PLS and CWT zero-crossing methods}

By comparing the results contained in tables 3 and 5 , it is clear that the statistical parameters of PLS ( $Q^{2}$ and RMSEP) are significantly better than those of CWT analysis. The better performances of PLS can be attributed to its multivariate character. CWT is only a preprocessing 
Citation: Shariati-Rad M, Irandoust M, Amini T, Ahmadi F (2012) Partial Least Squares and Continuous Wavelet Transformation in Simultaneous Spectrophotometric Determination of Amlodipin and Atorvastatine. Pharmaceut Anal Acta 3:178. doi:10.4172/2153-2435.1000178

Page 5 of 7

\begin{tabular}{|c|c|c|c|c|c|c|c|c|c|}
\hline Analyte & NuNumber of LVs & RMSECV & RMSEP & $R_{\text {test }}^{2}$ & $Q_{t e s t}^{2}$ & SEL & SEN & LOD & Y \\
\hline AM & 4 & 0.087 & 0.169 & 0.987 & 0.981 & 0.354 & 0.300 & 0.496 & 68.804 \\
\hline AT & 3 & 0.267 & 0.927 & 0.980 & 0.974 & 0.348 & 0.956 & 0.156 & 219.010 \\
\hline
\end{tabular}

Table 3: Performance characteristics of PLS upon application to the calibration and external test set in Table 2.

\begin{tabular}{|c|c|c|c|c|c|}
\hline Analyte & $\lambda(\mathrm{nm})$ & Dynamic linear range $\left(\mathrm{mg} \mathrm{L}^{-1}\right)$ & Regression equation & $R^{2}$ & LOD $\left(\mathrm{mg} \mathrm{L}^{-1}\right)$ \\
\hline \multicolumn{6}{|l|}{ AM } \\
\hline & 238 & $1.7-20$ & $S=0.019 C_{A M}-0.0125$ & 0.981 & 0.074 \\
\hline & 268 & $1.7-20$ & $S=-0.0229 C_{A M}+0.0187$ & 0.967 & 0.011 \\
\hline & 269 & $1.7-20$ & $\mathrm{~S}=-0.0228 \mathrm{C}_{\mathrm{AM}}+0.0183$ & 0.968 & 0.010 \\
\hline & 270 & $1.7-20$ & $S=-0.0224 C_{A M}+0.02$ & 0.965 & 0.010 \\
\hline \multicolumn{6}{|l|}{ AT } \\
\hline & 235 & 3.6-35 & $S=-0.019 C_{A T}-0.0283$ & 0.991 & 0.079 \\
\hline & 256 & $2.2-35$ & $S=0.012 C_{A T}-0.0184$ & 0.986 & 0.037 \\
\hline & 309 & $2.2-35$ & $\mathrm{~S}=-0.0167 \mathrm{C}_{\mathrm{AT}}+0.0098$ & 0.991 & 0.013 \\
\hline & 310 & $2.2-35$ & $S=-0.018 C_{A T}+0.008$ & 0.993 & 0.010 \\
\hline
\end{tabular}

Table 4: Statistical results of calibration curves at zero-cross points for AM and AT.

method and the analyses are eventually performed on the transformed data as zero order data. Results of PLS are better than those of CWT even at its best circumstances $(\lambda=238$ and $256 \mathrm{~nm}$ for AM and AT, respectively).

If we consider the results of CWT zero-crossing in the two mentioned wavelengths in application to real pharmaceutical samples,

\begin{tabular}{|c|c|c|c|c|}
\hline & $\lambda(\mathrm{nm})$ & RMSEP & $R_{\text {test }}^{2}$ & $Q_{\text {test }}^{2}$ \\
\hline AM & & & & \\
\hline & 238 & 0.281 & 0.960 & 0.953 \\
\hline & 268 & 0.506 & 0.914 & 0.849 \\
\hline & 269 & 0.498 & 0.917 & 0.854 \\
\hline & 270 & 0.524 & 0.909 & 0.838 \\
\hline & & & & \\
\hline & 235 & 1.107 & 0.968 & 0.966 \\
\hline & 256 & 0.968 & 0.975 & 0.974 \\
\hline & 309 & 1.075 & 0.972 & 0.968 \\
\hline & 310 & 1.027 & 0.974 & 0.971 \\
\hline
\end{tabular}

Table 5: Statistical performances of CWT zero-crossing in external test set prediction.

\begin{tabular}{|c|c|c|c|c|c|}
\hline Brand 1 & & Declared content $(\mathrm{mg})$ & Found $^{\mathrm{a}}(\mathrm{mg})$ & Recovery $\%$ & RSD $\%$ \\
\hline & AM & 5 & $5.04 \pm 0.05$ & 100.7 & 0.81 \\
\hline & AT & 20 & $19.72 \pm 0.61$ & 98.6 & 3.07 \\
\hline Brand 2 & AM & 5 & $5.07 \pm 0.04$ & 101.4 & 0.80 \\
\hline & AT & 20 & $20.02 \pm 0.38$ & 100.1 & 1.88 \\
\hline
\end{tabular}

Mean of five determinations

Table 6: Results of application of PLS models on the spectra of the pharmaceutical preparations.

\begin{tabular}{|c|c|c|c|c|c|}
\hline & $\lambda(\mathrm{nm})$ & Declared content $(\mathrm{mg})$ & Found $^{\mathrm{a}}(\mathrm{mg})$ & Recovery $\%$ & RSD $\%$ \\
\hline AM & & & & & \\
\hline Brand 1 & & & & & \\
\hline & 238 & 5 & $4.34 \pm 0.06$ & 86.9 & 1.41 \\
\hline & 268 & 5 & $5.54 \pm 0.02$ & 110.8 & 0.38 \\
\hline & 269 & 5 & $5.52 \pm 0.02$ & 110.4 & 0.37 \\
\hline & 270 & 5 & $5.51 \pm 0.02$ & 110.3 & 0.37 \\
\hline Brand 2 & & & & & \\
\hline & 238 & 5 & $4.28 \pm 0.11$ & 85.6 & 2.68 \\
\hline & 268 & 5 & $5.45 \pm 0.10$ & 109.0 & 1.75 \\
\hline & 269 & 5 & $5.45 \pm 0.08$ & 109.1 & 1.41 \\
\hline & 270 & 5 & $5.47 \pm 0.06$ & 109.4 & 1.08 \\
\hline AT & & & & & \\
\hline Brand 1 & & & & & \\
\hline & 235 & 20 & $20.88 \pm 0.03$ & 104.4 & 0.15 \\
\hline & 256 & 20 & $19.52 \pm 0.03$ & 97.6 & 0.16 \\
\hline & 309 & 20 & $19.93 \pm 0.01$ & 99.7 & 0.04 \\
\hline & 310 & 20 & $19.79 \pm 0.01$ & 98.9 & 0.07 \\
\hline Brand 2 & & & & & \\
\hline & 235 & 20 & $20.88 \pm 0.03$ & 104.4 & 0.13 \\
\hline & 256 & 20 & $19.51 \pm 0.02$ & 97.5 & 0.12 \\
\hline & 309 & 20 & $19.93 \pm 0.01$ & 99.7 & 0.04 \\
\hline & 310 & 20 & $19.78 \pm 0.01$ & 98.9 & 0.06 \\
\hline
\end{tabular}

${ }^{a}$ Mean of five determinations.

Table 7: Results of application of CWT zero-crossing method on the spectra of the pharmaceutical preparations.

the results of PLS are yet better. This statement is especially true in determination of AM. Also, in all of the other wavelengths, PLS performances are better for AM. However, for AT determination in pharmaceutical preparations, recoveries of CWT zero-crossing in the other wavelengths are comparables with those of PLS.

For a more precise statistical comparison of the two methods $t$ values were calculated [32]. For AM, $t$ values of 512.51 and 243.25 and 
Citation: Shariati-Rad M, Irandoust M, Amini T, Ahmadi F (2012) Partial Least Squares and Continuous Wavelet Transformation in Simultaneous Spectrophotometric Determination of Amlodipin and Atorvastatine. Pharmaceut Anal Acta 3:178. doi:10.4172/2153-2435.1000178

Page 6 of 7

for AT, 1.78 and 1.97 were obtained in analyzing Brand 1 and Brand 2, respectively. It must be mentioned for this comparison the best results of CWT zero-crossing have been used. Considering 5 determinations in each case, the degree of freedom will be 8 with the tabulated $t$ value of 2.36 ( $p=0.05)$. Therefore, the accuracy of the PLS method is significantly better than that of CWT zero-crossing in AM determination but there is no significant difference in determination of AT.

Due to its multivariate character, PLS is not largely affected by fluctuations raised from random errors (noise) from one determination to another. Therefore, it is more accurate than CWT zero-crossing method which uses signal at only single wavelengths.

RSD\% values obtained with two methods in AM determinations are comparable but in pharmaceutical analysis for AT, CWT zerocrossing method seems to be more precise than PLS.

\section{Conclusions}

In the rare reports published, the methods for the simultaneous determination of amlodipin and atorvastatine recommend analysis by HPLC. Nonetheless, these methods are time consuming and require the use of large volumes of HPLC-grade solvents. In this paper, a novel analytical method for the simultaneous determination of amlodipin and atorvastatine in pharmaceutical preparations by using partial least squares was demonstrated. Results of application to pharmaceutical preparations indicate that this method can be easily and conveniently used for the routine quality control of the drugs in pharmaceutical dosage forms. Also, the method can be used instead of the conventional HPLC in order to minimize cost of analysis and the toxic wastes produced during the analysis.

PLS results were compared with those of CWT zero-crossing method. The results indicate the superiority of PLS method.

\section{References}

1. O'Neil MJ, Smith A, Heckelman PE, Budavari S (2001) The Merck Index, an Encyclopedia of Chemicals, Drugs and Biologicals. (13thedn), Merck \& Co. Inc., White House Station, New Jersey 488: 865.

2. McEvoy GK (2001) American Hospital Formulary Service ${ }^{\circledR}$. American Society of Health-System Pharmacists Inc., Bethesda 488: 865.

3. Sweetman SC (2005) Dose adjustment in renal impairment: response from Martindale: the Complete Drug Reference. BMJ 331: 292-293.

4. Mohammadi A, Rezanour N, Ansari DM, Ghorbani BF, Hashem M, et al. (2007) A stability-indicating high performance liquid chromatographic (HPLC) assay for the simultaneous determination of atorvastatin and amlodipine in commercial tablets. J Chromatogr B Analyt Technol Biomed Life Sci 846: 215-221.

5. Tatar S, Atmaca S (2001) Determination of amlodipine in human plasma by high-performance liquid chromatography with fluorescence detection. $J$ Chromatogr B Biomed Sci Appl 758: 305-310.

6. Quaglia MG, Barbato F, Fanali S, Santucci E, Donati E, et al. (2005) Direct determination by capillary electrophoresis of cardiovascular drugs, previously included in liposomes. J Pharm Biomed Anal 37: 73-79.

7. Gazy AA (2004) Determination of amlodipine besylate by adsorptive squarewave anodic stripping voltammetry on glassy carbon electrode in tablets and biological fluids. Talanta 62: 575-582.

8. Borek-Dohalský V, Huclovái J, Barrett B, Nemec B, Ulc I, et al. (2006) Validated HPLC-MS-MS method for simultaneous determination of atorvastatin and 2-hydroxyatorvastatin in human plasma-pharmacokinetic study. Anal Bioanal Chem 386: 275-285.

9. Rahman N, Azmi SNH (2000) Spectrophotometric Determination of Amlodipin Besylate by Charge-Transfer Complex Formation with p-Chloranilic Acid. Anal Sci 16: 1353-1356.
10. Sridhar K, Sastry CS, Reddy MN, Sankar DG, Srinivas KR (1997) Spectrophotometric Determination of Amlodipin Besylate in Pure Forms and Tablets. Anal Lett 30: 121-133.

11. Pandya KK, Satia M, Gandhi TP, Modi IA, Modi RI, et al. (1995) Detection and determination of total amlodipin by high-performance thin-layer chromatography: a useful technique for pharmacokinetic studies. J Chromatogr B Biomed Appl 667: 315-320.

12. Bahrami G, Mohammadi B, Mirzaeei S, Kiani A (2005) Determination of atorvastatine in human serum by reversed-phase high-performance liquid chromatography with UV detection. J Chromatogr B Analyt Technol Biomed Life Sci 826: 41-45.

13. Erk N (2004) Development of Electrochemical Methods for Determination of Atorvastatine and Analytical Application to Pharmaceutical Products and Spiked Human Plasma. Crit Rev Anal Chem 34: 1-7.

14. Ertürk S, Sevinç Aktaş E, Ersoy L, Fiçiciolu S (2003) An HPLC method for the determination of atorvastatin and its impurities in bulk drug and tablets. $J$ Pharm Biomed Anal 33: 1017-1023.

15. Ertürk S, Onal A, Müge CS (2003) Analytical methods for the quantitative determination of 3-hydroxy-3-methylglutaryl coenzyme A reductase inhibitors in biological samples. J Chromatogr B Analyt Technol Biomed Life Sci 793 193-205.

16. Miao XS, Metcalfe CD (2003) Determination of cholesterol-lowering statin drugs in aqueous samples using liquid chromatography-electrospray ionization tandem mass spectrometry. J Chromatogr A 998: 133-141.

17. Miao XS, Metcalfe CD (2003) Determination of pharmaceuticals in aqueous samples using positive and negative voltage switching microbore liquid chromatography/electrospray ionization tandem mass spectrometry. J Mass Spectrom 38: 27-34.

18. Freddy H, Chaudhari V (2005) Simultaneous Determination of Atorvastatine Calcium and Amlodipin Besylate from Pharmaceutical Formulation by Reversed Phase High Performance Liquid Chromatography. Asian J Chem 17 2502-2508.

19. Steele D (1989) Multivariate calibration. Sprectrochim Acta A Mol Biomo Sprectosc 46: 419 .

20. Geladi P, Kowalski BR (1986) Partial least-squares regression: a tutorial. Ana Chim Acta 185: 1-17.

21. Afkhami A, Abbasi-Tarighat M (2009) Application of continuous wavele transformation to the simultaneous kinetic determination of binary mixtures. Talanta 78: 424-431.

22. Dinç $\mathrm{E}$, Baleanu D (2003) Multidetermination of thiamine $\mathrm{HCl}$ and pyridoxine $\mathrm{HCl}$ in their mixture using continuous daubechies and biorthogonal wavele analysis. Talanta 59: 707-717.

23. Dinç E, Ozdemir A, Baleanu D (2005) An application of derivative and continuous wavelet transforms to the overlapping ratio spectra for the quantitative multiresolution of a ternary mixture of paracetamol, acetylsalicylic acid and caffeine in tablets. Talanta 65: 36-47.

24. Martens H, Jensen SA (1983) Partial least squares regression: a new two stage NIR calibration method. In: Holas J, Kratochvil J(eds.). Progress in Cereal Chemistry and Technology. Elsevier: Amsterdam. 607-647.

25. Ritter C (2000) Wavelets in Chemistry. In: Walczak B (Ed.), Elsevier Amsterdam. J Chemom 16: 607.

26. http://users.rowan.edu/ polikar/wavelets/wttutorial.html

27. Massart DL, Vandeginste BGM, Buydens LMC (1998) Handbook of Chemometrics and Qualimetrics: Part B Elsevier Amsterdam.

28. Haaland DM, Thomas EV (1988) Partial Least-Squares Methods for Spectra Analyses, 1. Relation to Other Quantitative Calibration Methods and the Extraction of Qualitative Information. Anal Chem 60: 1193-1202.

29. Lorber A, Faber K, Kowalski BR (1997) Net analyte signal calculation in multivariate calibration. Anal Chem 60: 1620-1626.

30. Clayton CA, Hines JW, Elkins PD (1987) Detection limits with specified assurance probabilities. Anal Chem 59: 2506-2514. 
Citation: Shariati-Rad M, Irandoust M, Amini T, Ahmadi F (2012) Partial Least Squares and Continuous Wavelet Transformation in Simultaneous Spectrophotometric Determination of Amlodipin and Atorvastatine. Pharmaceut Anal Acta 3:178. doi:10.4172/2153-2435.1000178

Page 7 of 7

31. Booksh KS, Kowalski BR (1994) Theory of analytical chemistry. Anal Chem 66: 782A-791A.

32. Miller JN, Miller JC (2005) Statistics and Chemometrics for Analytical Chemistry. (5thedn), Pearson Eduction Limited, Harlow.

33. Kennard RW, Stone LA (1969) Computer aided design of experiments. Technometrics 11: 137-148. 